10

\title{
Упругость и неупругость объемных кристаллов нитрида галлия
}

\author{
( Л.И. Гузилова, Б.К. Кардашев, А.И. Печников, В.И. Николаев \\ Физико-технический институт им. А.Ф. Иофрфе РАН, \\ 194021 Санкт-Петербург, Россия \\ e-mail: guzilova@mail.ioffe.ru
}

Поступило в Редакцию 25 января 2019 г.

В окончательной редакции 20 марта 2019 г.

Принято к публикации 11 июля 2019 г.

\begin{abstract}
Приведены результаты акустического исследования упругих и микропластических свойств двух типов больших образцов квазиобъемного $\mathrm{GaN}$, полученных методом хлорид-гидридной эпитаксии. Первый тип это поликристаллические образцы, текстурированные вдоль одного из кристаллографических направлений, второй - монокристаллы с характерными V-образными дефектами. Полученные результаты сопоставлены с литературными данными и проанализированы на основе существующих теоретических представлений о влиянии дислокаций и границ зерен на акустические и механические свойства кристаллов.
\end{abstract}

Ключевые слова: нитрид галлия, предел упругости, модуль Юнга.

DOI: 10.21883/JTF.2020.01.48675.24-19

\section{Введение}

Нитрид галлия $(\mathrm{GaN})$ в настоящее время широко применяется для производства устройств силовой и оптоэлектроники и вызывает огромный интерес у исследователей. Несмотря на большой объем накопленных сведений о свойствах $\mathrm{GaN}[1,2]$, все еще остаются недостаточно изученными его упругие и пластические свойства. Это связано с тем, что для достоверности таких исследований требуются достаточно крупные образцы, которые в силу ряда причин были ранее недоступны. Поэтому исследования механических свойств $\mathrm{GaN}$ до сих пор проводились теми методиками, которые могли быть адаптированы для измерений на тонких пленках и малоразмерных кристаллах. Как правило, использовались методы рентгеновской дифракции [3], брюллюэновского рассеяния [4,5], микро- и наноиндентирования [6,7], в дополнение к которым проводились расчеты из первых принципов [8].

В настоящей работе для исследования механических (упругих и микропластических) свойств $\mathrm{GaN}$ использовалась акустическая методика. Измерения проводились с помощью составного пьезоэлектрического вибратора, представляющего собой кристалл пьезокварца с приклеенным к его торцу образцом. Данная методика позволяет с высокой точностью произвести оценку модуля упругости $E$ и логарифмического декремента $\delta$, являющегося мерой затухания звука в образце. Следует отметить, что для этих исследований требуются образцы определенной длины, обычно более 20-30 mm. В силу сложности и трудоемкости процессов получения больших кристаллов $\mathrm{GaN}$ [9], вырастить кристаллы с таким линейным размером возможно далеко не во всех кристаллографических направлениях. Существующие технологии роста кристаллов $\mathrm{GaN}$ [9-12] позволяют получать лишь единичные, а иногда и уникальные объекты, которые могли бы удовлетворить требованиям, предъявляемым к образцам для акустических исследований.

\section{Образцы и методика эксперимента}

В настоящей работе исследовались моно- и поликристаллы так называемого квазиобъемного GaN. Технология их получения основана на процессе хлорид-гидридной эпитаксии (ХГЭ) [10-12].

Надо заметить, что большие монокристаллы, полученные по технологии ХГЭ, имеют крупные V-образные дефекты (питы), в некоторых случаях пронизывающие всю толщину кристалла (рис. 1) [12]. Питы в виде правильных и строго ориентированных шестигранных пирамид распространяются по мере роста кристалла от подложки к ростовой поверхности, постепенно увеличиваясь в поперечном сечении.

В полученных тем же способом поликристаллических образцах [11] таких дефектов не наблюдается, они выглядят монолитными.

Поликристаллические и монокристаллические пластины GaN были получены в однотипных технологических условиях. Первые - результат газотранспортного осаждения на керамическую подложку из пиролитического h-BN, вторые - продукт эпитаксиального роста на стандартной сапфировой подложке. И те, и другие при достижении некоторой толщины самопроизвольно отделялись от подложек внутри газотранспортного реактора.

Образцы для исследований в виде прямоугольных стержней вырезались алмазной пилой из кристаллических пластин $\mathrm{GaN}$, полученных в процессе ХГЭ.

Эпитаксиальная монокристаллическая пластина $\mathrm{GaN}$, выращенная по форме своей подложки (диска с диаметром $50.8 \mathrm{~mm}$ ), имела, согласно законам эпитаксии, выраженную кристаллографическую ориентацию по всем направлениям. Перпендикулярно подложке располага- 


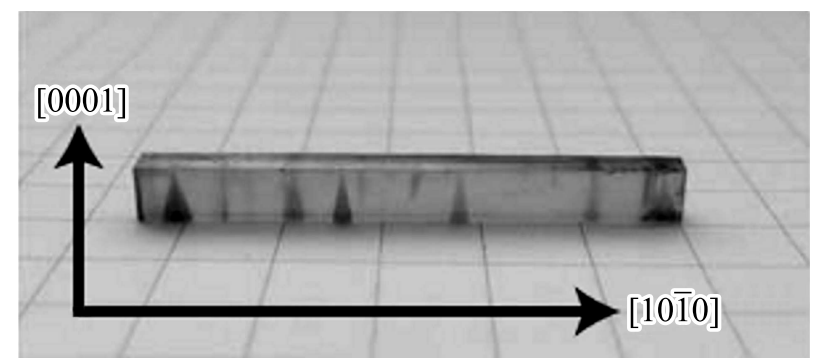

Рис. 1. Образец для акустических исследований, вырезанный из толстой эпитаксиальной пленки $\mathrm{GaN}$.

лась ось [0001]. Из пластины был вырезан стержень прямоугольной формы, ориентированный вдоль длинной стороны по направлению [10피. Как упоминалось выше (рис. 1), монокристаллический образец $\mathrm{GaN}$ содержал крупные $\mathrm{V}$-образные ростовые дефекты (питы). С целью снижения количества этих дефектов в исследуемом образце вырезаемое место на пластине тщательно выбиралось.

Методом рентгеновской дифракции было обнаружено, что поликристаллические образцы имели структуру $2 H$-GaN. Нормаль к их ростовой поверхности соответствует направлению [1010]. Однако в перпендикулярном направлении, т.е. в плоскости подложки, какая-либо определенная кристаллографическая ориентация не проявлялась. Для учета возможного влияния технологического фактора на анизотропию свойств этих образцов принималась во внимание их ориентация по отношению к направлению основного газового потока в реакторе. Поликристаллические образцы вырезались вдоль и поперек потока транспортного газа.

Все образцы как поликристаллические, так и монокристаллические имели длину $\sim 27 \mathrm{~mm}$ и квадратное поперечное сечение $\sim 2.8 \times 2.8 \mathrm{~mm}$. Такая длина обеспечивала резонанс продольных колебаний на частоте около $100 \mathrm{kHz}$.

Для исследований упругих и микропластических свойств объемных образцов $\mathrm{GaN}$ использовался акустический метод составного пьезоэлектрического вибратоpa $[13,14]$. Суть метода заключается в возбуждении пьезокварцем продольной стоячей ультразвуковой волны в составном вибраторе (акустической системе, состоящей из пьезокварца и образца).

При проведении эксперимента с использованием данной акустической методики использовалась установка, состоящая из трех основных частей: моста переменного тока с составным вибратором (пьезокварц включается в одно из плеч моста переменного тока), системы подачи возбуждающего электрического напряжения и системы измерения резонансной частоты. Стоит отметить, что в данной схеме измерений один кварцевый преобразователь служит как источником, так и приемником сигнала. В ходе эксперимента регистрируются три параметра: возбуждающее напряжение, ток через кварц в момент резонанса, когда этот ток имеет максимальное значение на определенной (резонансной) частоте возбуждающего напряжения, и резонансная частота. Этих параметров достаточно, чтобы определить декремент $\delta$, резонансную частоту $f$, амплитуду колебательной деформации $\varepsilon$ и модуль упругости исследуемого образца. Амплитуда пропорциональна току, проходящему через кварц, декремент - эквивалентному электрическому сопротивлению кварца или кварца с образцом. Соответствующие формулы можно найти в [13].

Зная резонансные частоты составного вибратора $f_{2}$ и пьезокварца $f_{q}$, можно вычислить резонансную частоту образца $f$ :

$$
f_{m}=f_{2} m_{2}-f_{q} m_{q} .
$$

Здесь $m, m_{q}, m_{2}$ - массы образца, кварца и составного (двойного) вибратора.

По аналогичной формуле рассчитывается декремент образца $\delta$ :

$$
\delta m=\delta_{2} m_{2}-\delta_{q} m_{q},
$$

где $\delta_{2}$ и $\delta_{q}$ - декремент составного (двойного) вибратора и кварца соответственно.

Модуль упругости (Юнга) $E$ рассчитывается по формуле

$$
E=4 \rho(l f)^{2} .
$$

Здесь $\rho$ и $l-$ соответственно плотность и длина образца. Плотность образца определялась методом гидростатического взвешивания с относительной погрешностью менее $0.1 \%$. Для монокристаллического $\mathrm{GaN}$

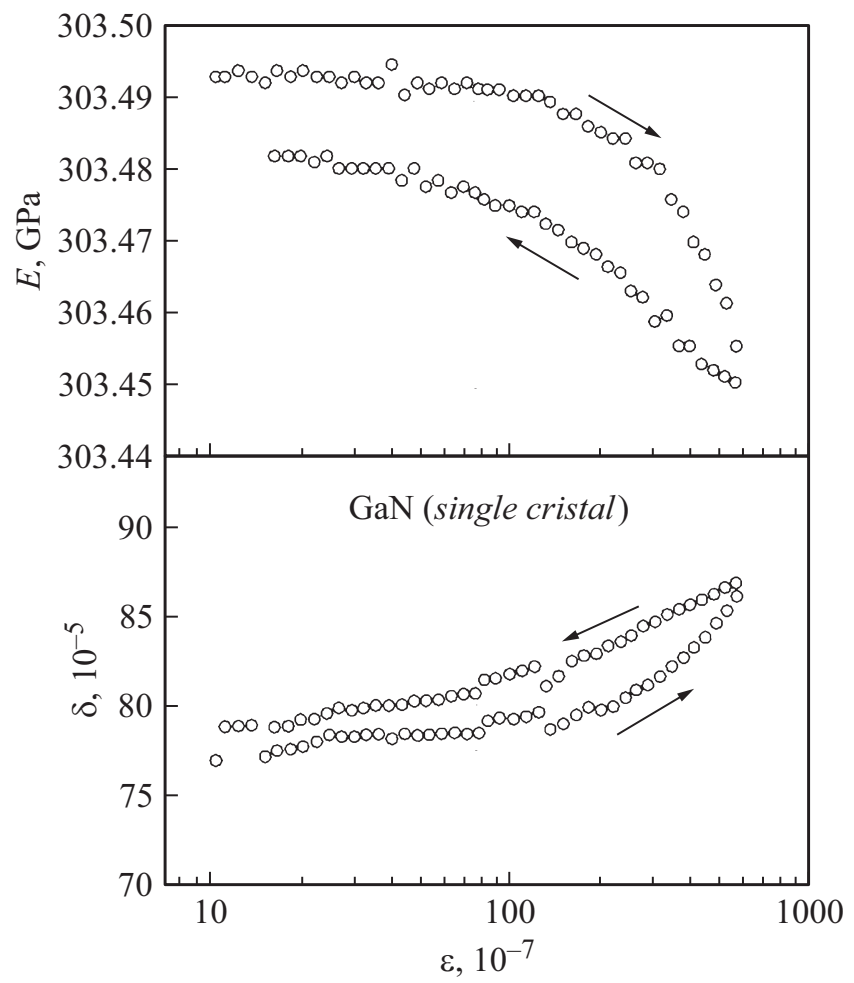

Рис. 2. Амплитудные зависимости модуля Юнга $E$ и декремента $\delta$ монокристаллического $\mathrm{GaN}$; измерения выполнены при комнатной температуре, стрелки указывают направление изменения амплитуды. 


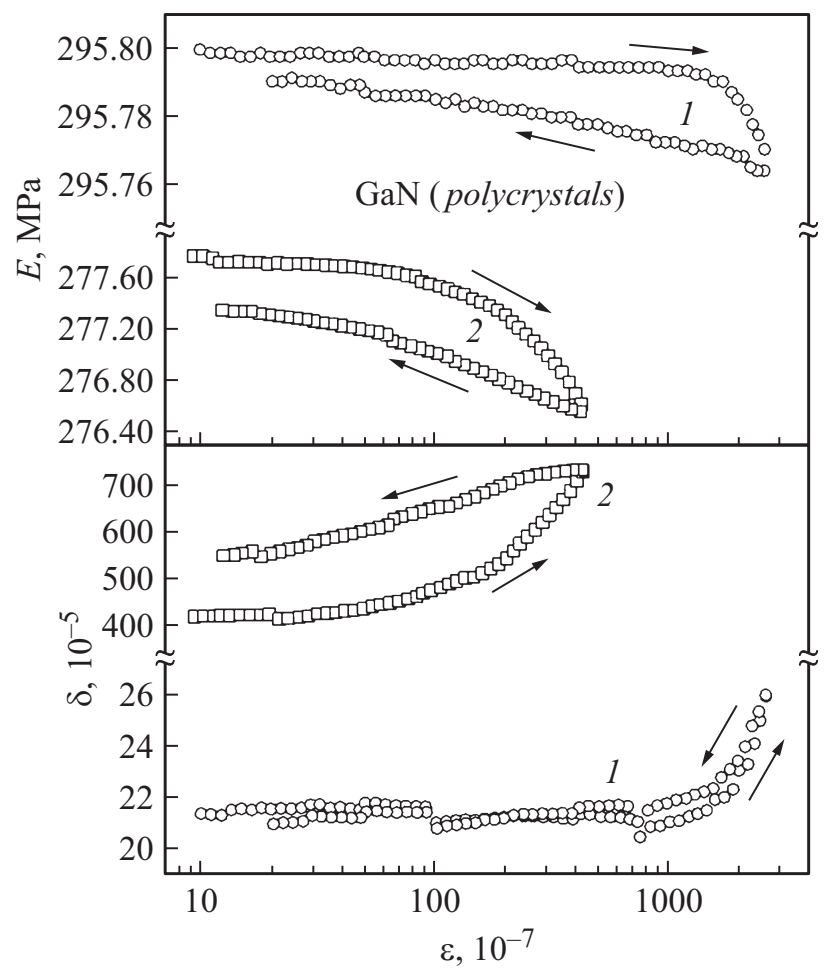

Рис. 3. Амплитудные зависимости модуля Юнга $E$ и декремента $\delta$ поликристаллов $\mathrm{GaN}: 1-$ в направлении газового потока, 2 - поперек потока; измерения выполнены при комнатной температуре, стрелки указывают направление изменения амплитуды.

она составляла величину $6.087 \mathrm{~g} / \mathrm{cm}^{3}$, для поликристалла $-6.1235 \mathrm{~g} / \mathrm{cm}^{3}$. Длины образцов измерялись на компараторе ИЗА-2 с погрешностью также менее $0.1 \%$. Частоты определялись с ошибкой порядка $10^{-4 \%} \%$. Таким образом, возможная ошибка в определении модуля Юнга для конкретного образца составляла величину не более $0.1-0.2 \%$.

По результатам измерений $E(\varepsilon)$ строились диаграммы микропластического деформирования $\sigma\left(\varepsilon_{d}\right)$ : здесь $\sigma=E \varepsilon$ (закон Гука), а $\varepsilon_{d}-$ нелинейная неупругая (микропластическая) деформация. Подробное описание процедуры подобных построений из экспериментальных данных можно найти в [14]. Здесь лишь отметим, что диаграммы $\sigma\left(\varepsilon_{d}\right)$ строились из зависимостей $E(\varepsilon)$, снятых при самом первом увеличении амплитуды $\varepsilon$ на образцах, ни разу не подвергавшихся воздействию высоких амплитуд.

\section{Результаты эксперимента и их обсуждение}

На рис. 2 и 3 представлены амплитудные зависимости модуля Юнга $E$ и логарифмического декремента $\delta$ для монокристалла и поликристаллов $\mathrm{GaN}$. Из рисунков видно, что для всех образцов имеет место амплитудный гистерезис: зависимости, измеренные последова- тельно при увеличении и уменьшении амплитуды, не совпадают друг с другом. Такое поведение характерно для пластичных кристаллических материалов [13,14], когда при достаточно высоких амплитудах наблюдается уменьшение измеряемого модуля упругости и увеличение декремента. С точки зрения теории зависящего от амплитуды внутреннего трения [15], эти эффекты могут быть связаны с нелинейной неупругой деформацией, обусловленной колебательным движением дислокаций в силовых полях стопоров - закрепляющих дислокации точечных дефектов.

На рис. 4 показаны диаграммы микропластического деформирования $\sigma\left(\varepsilon_{d}\right)$ образцов $\mathrm{GaN}$, построенные по данным рис. 2 и 3. Следует обратить внимание на тот факт, что пластичность $\mathrm{GaN}$ проявляется лишь в микропластической области на уровне деформаций $10^{-8}$ (т.е. $10^{-6} \%$ ). Макроскопической деформации при комнатной температуре в экспериментах на сжатие не наблюдалось, все образцы $\mathrm{GaN}$ разрушались хрупко.

На рис. 4 видно, что у поликристаллов наблюдается значительная анизотропия: уровень напряжений микропластического течения для образцов, вырезанных в различных направлениях газового потока при выращивании, отличается более чем на порядок. Это, скорее всего, связано с различной структурой границ зерен и, возможно, с кристаллографической текстурой, формирующейся при выращивании вдоль и поперек газового потока. Интересно отметить, что напряжения для поликристалла, вырезанного вдоль направления газового потока, оказались даже выше, чем у монокристаллического образца. Это можно объяснить как анизотропией модуля Юнга, так и недостаточным качеством монокристалла,

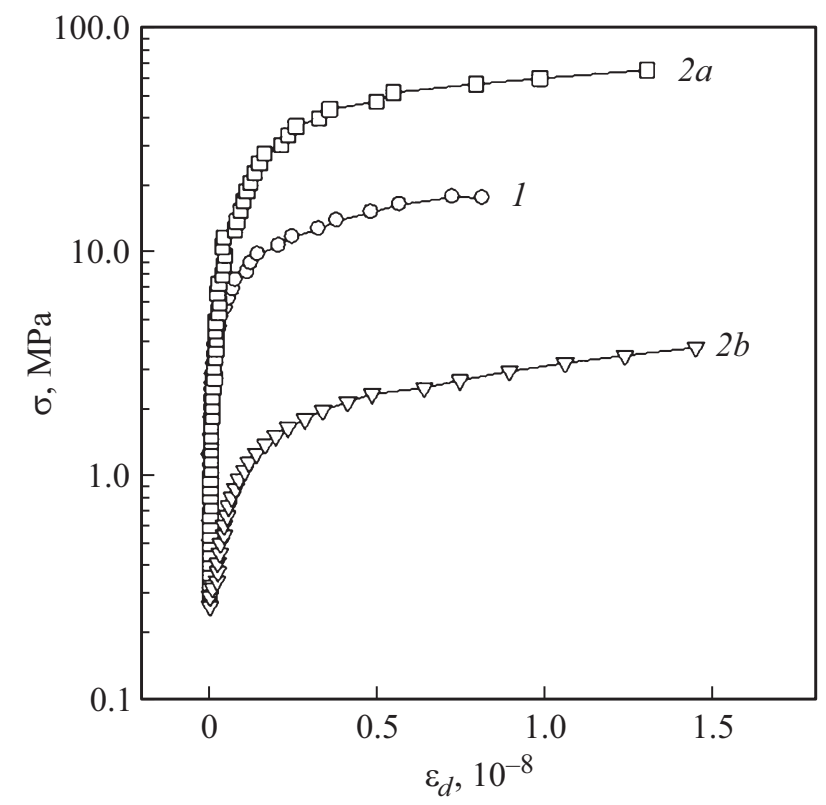

Рис. 4. Диаграммы $\sigma-\varepsilon_{d}$ микропластического деформирования объемных образцов $\mathrm{GaN}$ для комнатной температуры, построенные по данным акустических измерений; 1 монокристаллический образец, $2-$ поликристаллы: $a-$ в направлении потока, $b-$ поперек потока. 
Сравнительные данные значений модуля Юнга $\mathrm{GaN}$, полученные в результате экспериментальных исследований и расчетов

\begin{tabular}{|c|c|c|}
\hline & $\begin{array}{l}\text { Значение модуля } \\
\text { Юнга } E, \mathrm{GPa}\end{array}$ & Примечание \\
\hline Кристалл GaN [8] & 291.6 & $\begin{array}{l}\text { Расчет был выполнен из первых принципов методом линейных } \\
\text { muffin-tin (MT) орбиталей с полным потенциалом (FP-LMTO). }\end{array}$ \\
\hline Порошок [3] & 129.8 & $\begin{array}{l}\text { Модуль Юнга получен расчетом из данных среднеквадратичного } \\
\text { смещения атомов GaN, полученных методом рентгеновской дифракции. }\end{array}$ \\
\hline \multirow{2}{*}{$\begin{array}{l}\text { Эпитаксиальный слой } \\
\mathrm{GaN} \text { на } \mathrm{Al}_{2} \mathrm{O}_{3}[7]\end{array}$} & 284.2 & $\begin{array}{l}\text { Эпитаксиальный слой получен методом хлорид-гидридной эпитаксии (HVPE). } \\
\text { Модуль Юнга измерен методом наноиндентирования вдоль направления [1010]. }\end{array}$ \\
\hline & 323.8 & $\begin{array}{l}\text { Эпитаксиальный слой получен хлорид-гидридной эпитаксией (HVPE). Модуль } \\
\text { Юнга измерен методом наноиндентирования вдоль направления [0001] }\end{array}$ \\
\hline $\begin{array}{l}\text { Эпитаксиальный слой } \\
\mathrm{GaN} \text { на } \mathrm{Al}_{2} \mathrm{O}_{3}[4]\end{array}$ & 302.4 & $\begin{array}{l}\text { Эпитаксиальный слой был получен химическим осаждением из паров } \\
\text { металлорганических соединений (англ. MOCVD). Модуль Юнга } \\
\text { вычислен с помощью данных, полученных Брюллюэновским рассеянием }\end{array}$ \\
\hline Монокристалл [5] & 302.7 & $\begin{array}{l}\text { Выращенный монокристалл GaN имел игольчатый вид. Направление [0001]. Модуль } \\
\text { Юнга вычислен с помощью данных, полученных Брюллюэновским рассеянием. }\end{array}$ \\
\hline \multicolumn{3}{|r|}{ Данные, полученные в настоящей работе: } \\
\hline Монокристалл & $305.0^{*}$ & $\begin{array}{l}\text { Монокристалл был получен методом хлорид-гидридной эпитаксии (HVPE). Направ- } \\
\text { ление }[10 \overline{1} 0] . \text { Акустический метод составного пьезоэлектрического вибратора. }\end{array}$ \\
\hline \multirow{2}{*}{ Поликристалл } & $295.0^{*}$ & $\begin{array}{l}\text { Поликристалл был получен методом хлорид-гидридной эпитаксии (HVPE). } \\
\text { Технологическое направление - вдоль направления газового потока. } \\
\text { Акустический метод составного пьезоэлектрического вибратора. }\end{array}$ \\
\hline & $291.0^{*}$ & $\begin{array}{l}\text { Поликристалл был получен методом хлорид-гидридной эпитаксии (HVPE). } \\
\text { Технологическое направление - поперек направления газового потока. } \\
\text { Акустический метод составного пьезоэлектрического вибратора. }\end{array}$ \\
\hline
\end{tabular}

Примечание: * при комнатной температуре.

где имеется несколько больших пит, хорошо видных на рис. 1.

Для наглядности данные по упругим свойствам, имеющиеся в литературе, и данные, полученные в настоящей работе, сведены в таблицу. Видно, что экспериментальные значения модуля Юнга $E$ эпитаксиальных слоев, моно- и поликристаллов $\mathrm{GaN}$, выращенные разными методами, а также расчетные результаты, довольно близки друг к другу, и, несмотря на различие в кристаллографических направлениях, укладываются в интервал значений $E=284-305 \mathrm{GPa}$. Исключение составляют лишь результаты самой ранней работы, где модуль Юнга был получен для порошкообразного GaN [3]. Величина его оказалась значительно ниже. Это значение $E$ было вычислено в [3] с использованием данных о среднеквадратичных смещениях атомов в решетке $\mathrm{GaN}$, полученных из экспериментов по рентгеновской дифракции порошковых образцов. Поэтому эти результаты могут рассматриваться лишь как оценочные.

\section{Заключение}

В работе впервые исследованы упругие и неупругие свойства квазиобъемных кристаллов $\mathrm{GaN}$ как на поликристаллических, так и на монокристаллических образцах. Получены амплитудные зависимости внутреннего трения и модуля Юнга, построены диаграммы нагружения кристаллов $\mathrm{GaN}$ в координатах напряжение-неупругая деформация $\left(\sigma\left(\varepsilon_{d}\right)\right)$, из которых можно оценить условный предел упругости при любой фиксированной величине $\varepsilon_{d}$. Установлен хрупкий характер разрушения всех испытанных на сжатие образцов при комнатной температуре. Сделано обобщение данных об упругости $\mathrm{GaN}$ в различных исследованиях.

\section{Конфликт интересов}

Авторы заявляют, что у них нет конфликта интересов.

\section{Список литературы}

[1] Ueda D. // Power GaN Devices: Materials, Application and Reliability / Eds M. Meneghini, G. Meneghesso, E. Zanoni. Switzerland: Springer Nature, 2017. P. 1-26.

[2] Qin H., Luan X., Feng C., Yang D., Zhang G. // Materials. 2017. Vol. 10. Art. N 1419.

[3] Savastenko V.A., Sheleg A.U. // Phys. Stat. Solid. (A). 1978. Vol. 43. P. K135-K139. 
[4] Takagi Y., Ahart M., Azuhata T., Sota T., Suzuki K., Nakamura S. // Physica B. 1996. Vol. 219-220. P. 547-549.

[5] Polian A., Grimsditch M., Grzegory I. // J. Appl. Phys. 1996. Vol. 79. N 6. P. 3343-3344.

[6] Николаев В.И., Шиейзман В.В., Смирнов Б.И. // ФТТ. 2000. Т. 42. Вып. 3. С. 428-431. [Nikolaev V.I., Shpeizman V.V., Smirnov B.I. // Phys. Solid State. 2000. Vol. 42. N 3. P. 437-440.]

[7] Fujikane M., Inoue A., Yokogawa T., Nagao S., Nowak R. // Phys. Stat. Sol. C. 2010. Vol. 7. N 7-8. P. 1798-1800.

[8] Kim K., Lambrecht W.R.L., Segall B. // Phys. Rev. B. 1996. Vol. 53. N 24. P. 16310-16326.

[9] Zajac M., Kucharski R., Grabianska K., GwardysBak A., Puchalski A., Wasik D., Litwin-Staszewska E., Piotrzkowski R., Domagala J.Z., Bockowski M. // Progress in Crystal Growth and Characterization of Materials. 2018. Vol. 64. N 3. P. 63-74.

[10] Siche D., Zwierz R. // Crystal Research and Technology. 2018 Vol. 53. N 5. Art. N 1700224.

[11] Мынбаева М.Г., Печников А.И., Ситникова А.А., Кириленко Д.А., Лаврентьев А.А., Иванова Е.В., Николаев В.И. // Письма ЖТФ. 2015. Т. 41. Вып. 84. C. 84-90. [Mynbaeva M.G., Pechnikov A.I., Sitnikova A.A., Kirilenko D.A., Lavrent'ev A.A., Ivanova E.V., Nikolaev V.I. // Tech. Phys. Lett. 2015. Vol. 41. N 3. P. 246-248.]

[12] Voronenkov V., Tsyuk A., Gorbunov R., Lelikov Y., Rebane Y., Zubrilov A., Bochkareva N., Shreter Y., Latyshev P. // ECS Transactions. Montreal. 2011. Vol. 35. N 6. P. 91-97.

[13] Никаноров С.П., Кардашев Б.К. Упругость и дислокационная неупругость кристаллов. // М.: Наука, 1985. 254 с.

[14] Кардашев Б.К. // Кристаллография. 2009. Т. 54. № 6. C. 1074-1086. [Kardashev B.K. // Crystallography Reports. 2009. Vol. 54. N 6. P. 1021-1032.]

[15] Gremaud G. // Mater. Sci. Forum. 2001. Vol. 366-368. P. 178246. 